\title{
Database of Vascular Plants of Canada (VASCAN): a community contributed taxonomic checklist of all vascular plants of Canada, Saint Pierre and Miquelon, and Greenland
}

\author{
Peter Desmet', Luc Brouillet' \\ I Université de Montréal Biodiversity Centre, 4101 rue Sherbrooke est, H1X2B2, Montreal, Canada \\ Corresponding author: Peter Desmet (peter.desmet@umontreal.ca)
}

Academic editor: Vishwas Chavan | Received 19 March 2012 | Accepted 17 July 2013 | Published 24 July 2013

Citation: Desmet P, Brouillet L (2013) Database of Vascular Plants of Canada (VASCAN): a community contributed taxonomic checklist of all vascular plants of Canada, Saint Pierre and Miquelon, and Greenland. PhytoKeys 25: 55-67. doi: 10.3897/phytokeys.25.3100 Resource ID: GBIF key: 3f8a1297-3259-4700-91fc-acc4170b27ce

Resource citation: Brouillet L, Desmet P, Coursol F, Meades SJ, Favreau M, Anions M, Bélisle P, Gendreau C, Shorthouse D and contributors* (2010+). Database of Vascular Plants of Canada (VASCAN). 27189 records. Online at http://data.canadensys.net/vascan, http://dx.doi.org/10.5886/Y7SMZY5P, and http://www.gbif.org/dataset/3f8a12973259-4700-91fc-acc4170b27ce, released on 2010-12-10, version 24 (last updated on 2013-07-22). GBIF key: 3f8a1297-3259-4700-91fc-acc4170b27ce. Data paper ID: http://dx.doi.org/10.3897/phytokeys.25.3100

\begin{abstract}
The Database of Vascular Plants of Canada or VASCAN (http://data.canadensys.net/vascan) is a comprehensive and curated checklist of all vascular plants reported in Canada, Greenland (Denmark), and Saint Pierre and Miquelon (France). VASCAN was developed at the Université de Montréal Biodiversity Centre and is maintained by a group of editors and contributors. For every core taxon in the checklist (species, subspecies, or variety), VASCAN provides the accepted scientific name, the accepted French and English vernacular names, and their synonyms/alternatives in Canada, as well as the distribution status (native, introduced, ephemeral, excluded, extirpated, doubtful or absent) of the plant for each province or territory, and the habit (tree, shrub, herb and/or vine) of the plant in Canada. For reported hybrids (nothotaxa or hybrid formulas) VASCAN also provides the hybrid parents, except if the parents of the hybrid do not occur in Canada. All taxa are linked to a classification. VASCAN refers to a source for all name, classification and distribution information.
\end{abstract}

${ }^{*}$ see Appendix.

The article is also available on GitHub at https://github.com/peterdesmet/vascan-data-paper

Copyright Peter Desmet, Luc Brouillet. This is an open access article distributed under the terms of the Creative Commons Attribution License 3.0 (CC-BY), which permits unrestricted use, distribution, and reproduction in any medium, provided the original author and source are credited. 
All data have been released to the public domain under a CC0 waiver and are available through Canadensys and the Global Biodiversity Information Facility (GBIF). VASCAN is a service to the scientific community and the general public, including administrations, companies, and non-governmental organizations.

\section{Keywords}

VASCAN, Canadensys, Canada, Greenland, Saint Pierre and Miquelon, checklist, taxonomy, synonymy, hybrids, vernacular names, English, French, distribution, provinces, habit, open data

\section{Data published through}

The Canadensys repository: doi: 10.5886/1bft7W5f

\section{Project details}

\section{Project title}

Database of Vascular Plants of Canada (VASCAN)

\section{Personnel}

Data compilation editors: Luc Brouillet (Université de Montréal Biodiversity Centre): coordination, taxonomic and geographic compilation, Frédéric Coursol (Montreal Botanical Garden): taxonomic and geographic compilation, Susan Meades (Northern Ontario Plant Database): taxonomic compilation, Marc Favreau (Translation Bureau, Public Works and Government Services Canada): French vernacular names compilation, Marilyn Anions (botanist, Ottawa): English vernacular names compilation.

Development: Peter Desmet (Université de Montréal Biodiversity Centre): coordination and web design, Pierre Bélisle (Université de Montréal Biodiversity Centre): development, Christian Gendreau (Université de Montréal Biodiversity Centre): development and maintenance, David Shorthouse (Université de Montréal Biodiversity Centre): coordination, Patrick O’Reilley (Université de Montréal): initial data import.

\section{Funding}

Partial funding came from Parks Canada, the Canadian Biodiversity Information Facility (CBIF), NatureServe Canada, the Canadian Foundation for Innovation (CFI), and the Gouvernement du Québec (grant to the Université de Montréal Biodiversity Centre and Canadensys). Most of the compilation work, however, was contributed in kind by the home institution of each collaborator. 


\section{Study area description}

The study area occupies the northern half of North America (excluding Alaska). The area of Canada is 9,984,670 $\mathrm{km}^{2}$, of Greenland (or Kulaalit Nunaat, an autonomous country within the kingdom of Denmark) 2,166,086 km², and Saint Pierre and Miquelon (collectivité territoriale, France) $242 \mathrm{~km}^{2}$. The latter is $20 \mathrm{~km}$ off the coast of Newfoundland's Burin Peninsula and its characteristics are those of boreal eastern Canada. From west to east, the main physiographic regions are the Western Cordillera, the sedimentary Interior Plains, the Canadian and Greenland Shields (mostly igneous rocks), the sedimentary Great Lakes and St. Lawrences Lowlands, and the Appalachian Mountains. The sedimentary Hudson Bay Lowlands basin lies at the centre of the shield, a northern area of sedimentary plains and mountains. The Canadian Arctic borders the Arctic Ocean in northern Canada and northern Greenland. An ice cap covers $81 \%$ of Greenland.

The dominant vegetation type of the area is the boreal forest, which occupies much of Canada from Yukon and northeastern British Columbia to Newfoundland. To the north, Arctic tundra prevails: it can be divided into low Arctic (with a nearly continuous plant cover, sometimes shrubby) and high Arctic (including polar deserts); these types are the only ones found in Greenland. To the south of the boreal forest, from west to east, are the humid Pacific Coastal forest, the Cordilleran forest, the Prairie grasslands, the eastern temperate forests (southern Ontario and Quebec), and the Atlantic or Acadian forests.

The population of Canada is concentrated in a narrow belt along its border with the United States, where most of the impacts on ecosystems (urbanization, agriculture) is concentrated. Logging, mining, and hydroelectric development occur in the boreal forest, and mining is now rapidly developing in the Arctic. About 9.9\% (Environment Canada 2011) of the terrestrial area of Canada is protected $(7.5 \%$ according to the World Bank 2013) and 40\% of Greenland. Based on the data in VASCAN, the area harbors a total of 5,124 vascular plant species, 3,829 native and 1,295 introduced ( $25 \%$ of the flora). Of the native species of Canada, 156 are considered legally at risk, with a further 34 of conservation concern (COSEWIC 2009+).

\section{Design description}

The goal of the Database of Vascular Plants of Canada (VASCAN) is to provide an upto-date, documented checklist of the names of vascular plants in Canada, Greenland, and Saint Pierre and Miquelon, both scientific and vernacular, and the distribution of the plants at the provincial/territorial level.

VASCAN was developed from the need to validate vascular plant name and distribution data from eastern Canada (Ontario and eastward), Greenland, and Saint Pierre and Miquelon for the Flora of North America project (FNA) and from the need to provide French vernacular names for taxa present in Quebec in the FNA. It expanded when Parks Canada wanted to harmonize the names from vascular plant species lists of its parks across the country. At the time we also realized that - aside from The 
Flora of Canada by Scoggan (1978-1979) that was in need of updating - not only was there no standardized scientific name list for the country - despite worthwhile efforts from Kartesz (1999) and USDA NRCS (2011) - but also no standardized source of Canadian English and French vernacular names. Names used for plants in English Canada are not necessarily those used in the United States, and thus U.S. sources were not always appropriate for this goal. Finally, several national organizations, such as Parks Canada, Forest Canada, the Committee on the Status of Endangered Wildlife in Canada (COSEWIC), and NatureServe Canada, expressed the need for a web-based list of Canadian taxa, with data on provincial/territorial distribution.

\section{Taxonomic coverage}

This checklist covers all vascular plants (Equisetopsida, Tracheophyta) reported in the area described in the section 'Spatial Coverage' (Figure 1). The core taxa considered are species, subspecies or varieties, and their hybrids. For these taxa, we provide synonyms, the accepted and alternative French and English vernacular names, and the habit (tree, shrub, herb and/or vine) of the plant in Canada. For reported hybrids (nothotaxa or hybrid formulas) we also indicate the hybrid parents, except if the parents of the hybrid do not occur in Canada. This core information is not provided for higher taxa,

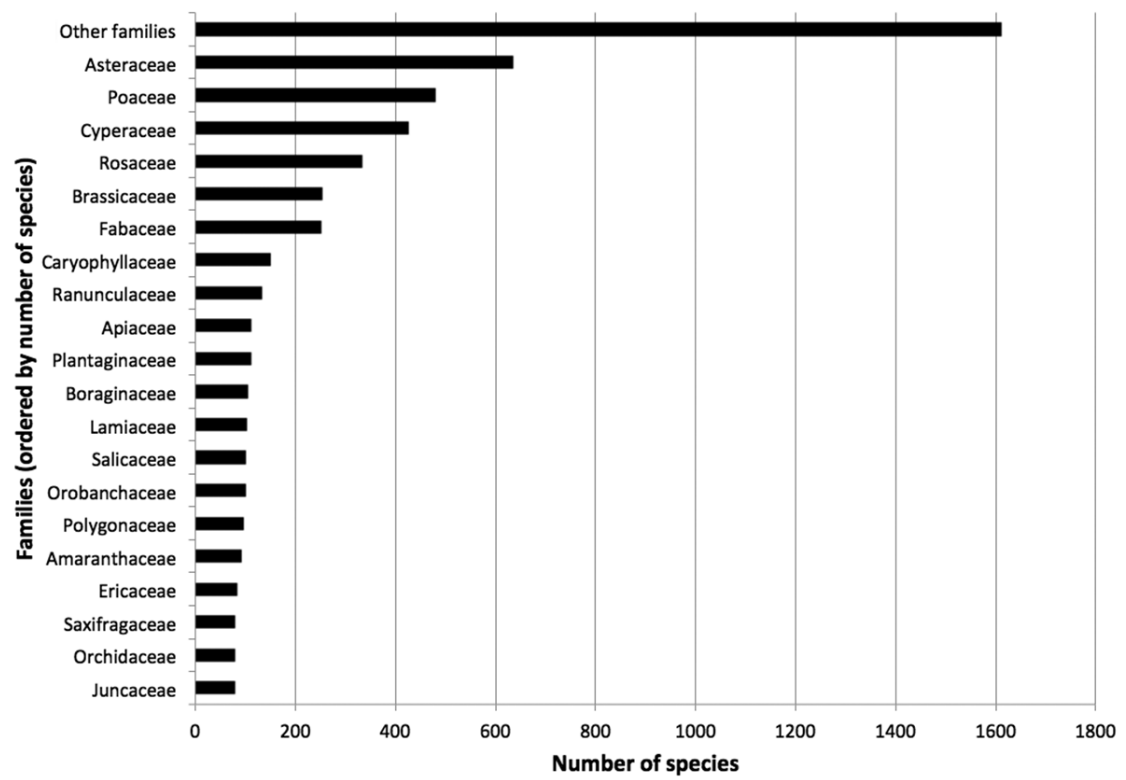

Figure I. Taxonomic distribution of accepted species per family from the Database of Vascular Plants of Canada (VASCAN). The families are ordered by total number of species. Families with less than 80 species are grouped in 'Other families'. 
although the calculated distribution based on lower taxa can be consulted and downloaded from the VASCAN website (http://data.canadensys.net/vascan).

All taxa are linked to a classification: Chase and Reveal (2009) for the higher classification, Christenhusz et al. (2011a) for lycophytes, Smith et al. (2006) for monilophytes (modified in Rothfells et al. 2012), Christenhusz et al. (2011b) for the gymnosperms, and the Angiosperm Phylogeny Group (2009) for flowering plants. At the generic level and below, the Flora of North America Editorial Committee (1993+) is the main source of classification, unless taxonomic literature more recent than the volume published for a given taxon provides a taxonomy more reflective of current data. The source used is indicated for each taxon in the dataset.

The classification includes 16 ranks. They are, in hierarchical order: class, subclass, superorder, order, family, subfamily, tribe, subtribe, genus, subgenus, section, subsection, series, species, subspecies and variety. Varieties within subspecies are accepted, so quadrinomial names are present, but forms are not included.

\section{Taxonomic ranks}

\section{Kingdom: Plantae}

\section{Class: Equisetopsida}

Family: Acanthaceae, Acoraceae, Adoxaceae, Alismataceae, Amaranthaceae, Amaryllidaceae, Anacardiaceae, Annonaceae, Apiaceae, Apocynaceae, Aquifoliaceae, Araceae, Araliaceae, Aristolochiaceae, Asparagaceae, Aspleniaceae, Asteraceae, Athyriaceae, Balsaminaceae, Berberidaceae, Betulaceae, Bignoniaceae, Blechnaceae, Boraginaceae, Brassicaceae, Butomaceae, Buxaceae, Cabombaceae, Cactaceae, Campanulaceae, Cannabaceae, Caprifoliaceae, Caryophyllaceae, Celastraceae, Ceratophyllaceae, Cistaceae, Cleomaceae, Clethraceae, Colchicaceae, Commelinaceae, Convolvulaceae, Cornaceae, Crassulaceae, Cucurbitaceae, Cupressaceae, Cyperaceae, Cystopteridaceae, Dennstaedtiaceae, Diapensiaceae, Dioscoreaceae, Droseraceae, Dryopteridaceae, Elaeagnaceae, Elatinaceae, Equisetaceae, Ericaceae, Eriocaulaceae, Euphorbiaceae, Fabaceae, Fagaceae, Frankeniaceae, Gentianaceae, Geraniaceae, Grossulariaceae, Haemodoraceae, Haloragaceae, Hamamelidaceae, Hydrangeaceae, Hydrocharitaceae, Hymenophyllaceae, Hypericaceae, Hypoxidaceae, Iridaceae, Isoëtaceae, Juglandaceae, Juncaceae, Juncaginaceae, Lamiaceae, Lauraceae, Lentibulariaceae, Liliaceae, Limnanthaceae, Linaceae, Linderniaceae, Loasaceae, Loranthaceae, Lycopodiaceae, Lythraceae, Magnoliaceae, Malvaceae, Marsileaceae, Martyniaceae, Melanthiaceae, Melastomataceae, Menispermaceae, Menyanthaceae, Molluginaceae, Montiaceae, Moraceae, Myricaceae, Nartheciaceae, Nelumbonaceae, Nyctaginaceae, Nymphaeaceae, Oleaceae, Onagraceae, Onocleaceae, Ophioglossaceae, Orchidaceae, Orobanchaceae, Osmundaceae, Oxalidaceae, Paeoniaceae, Papaveraceae, Penthoraceae, Phrymaceae, Phytolaccaceae, Pinaceae, Plantaginaceae, Platanaceae, Plumbaginaceae, Poaceae, Podostemaceae, Polemoniaceae, Polygalaceae, Polygonaceae, Polypodiaceae, Pontederiaceae, Portulacaceae, Potamogetonaceae, Primulaceae, Pteridaceae, Ranunculaceae, Resedaceae, Rhamnaceae, Rosaceae, Rubiaceae, Ruppiaceae, Rutaceae, Salicaceae, Salviniaceae, Santalaceae, Sapindaceae, Sarraceniaceae, Saururaceae, Saxifragaceae, 
Scheuchzeriaceae, Schizaeaceae, Scrophulariaceae, Selaginellaceae, Simaroubaceae, Smilacaceae, Solanaceae, Staphyleaceae, Tamaricaceae, Taxaceae, Thelypteridaceae, Thymelaeaceae, Tofieldiaceae, Typhaceae, Ulmaceae, Urticaceae, Verbenaceae, Violaceae, Vitaceae, Woodsiaceae, Xanthorrhoeaceae, Xyridaceae, Zosteraceae, Zygophyllaceae.

\section{Common names}

Vascular plants, Lycopods, ferns, conifers, flowering plants. In the dataset, French and English vernacular names are provided for families, species, subspecies, and varieties.

\section{Spatial coverage}

The checklist covers all vascular plants reported in Canada, Greenland (Denmark), and Saint Pierre and Miquelon (France) (Figure 2). The latter two regions are added because their floras are intimately related to that of Canada and it is useful for Canadians and others to know about them. Provincial distributions are provided to help Canadians visualize the relationship among the floras of their provinces and territories. VASCAN does not intend to replace regional or provincial lists but to act as a complement to them. The covered regions are, in alphabetical order: Alberta, British Columbia, Greenland, Labrador, Manitoba, New Brunswick, Newfoundland, Northwest Territories, Nova Scotia, Nunavut, Ontario, Prince Edward Island, Quebec, Saint Pierre and Miquelon, Saskatchewan, and Yukon.

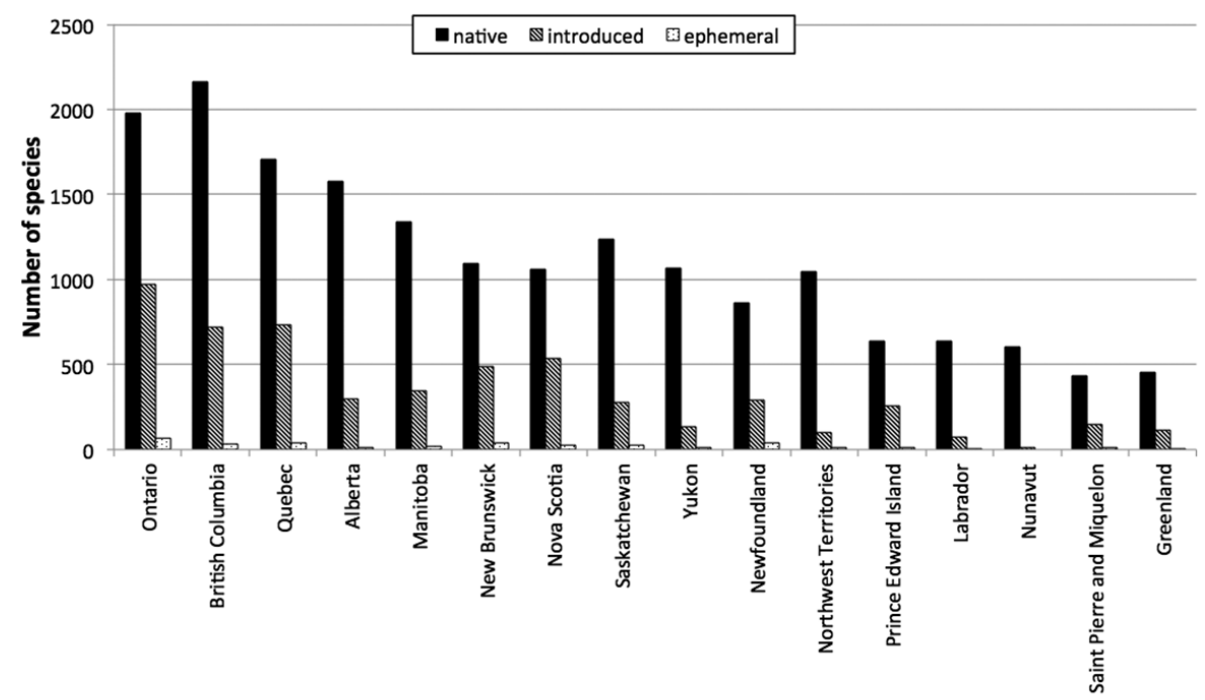

Regions (ordered by total number of species)

Figure 2. Regional distribution of accepted species from the Database of Vascular Plants of Canada (VASCAN). For each region, the number of native, introduced and ephemeral species is shown, i.e. species with a confirmed presence in the region. The regions are ordered by total number of species. 
The distribution status of the plant is indicated per region. These can be grouped as present (native, introduced or ephemeral), previously reported but currently considered absent (excluded, extirpated), doubtful or not reported (absent). The latter status is not recorded in the database (null value). Excluded taxa are those considered not currently occurring in a region, due either to non-recurring ephemeralness, misidentification, lack of supporting documentation, or when specimens are old and the taxon has not been observed again in more than 50 years. All distribution statuses are defined at http://data.canadensys.net/vascan/about/\#distribution.

The VASCAN website (http://data.canadensys.net/vascan) provides a distribution map for each taxon. For higher taxa, these are calculated based on lower taxa, with the distribution statuses ordered as such: native, introduced, ephemeral, excluded, extirpated, doubtful, absent. E.g., if two species within the same genus are respectively native and doubtful in a certain region, the genus is considered native for that region.

The website also provides a checklist builder (http://data.canadensys.net/vascan/ checklist), where users can generate their own list of taxa based on several criteria (taxonomy, region, distribution status, or a combination of these) and download this as a Darwin Core Archive or text file.

Bounding box for covered area

$41^{\circ} 40^{\prime} \mathrm{N}$ and $83^{\circ} 40^{\prime} \mathrm{N}$ latitude; $141^{\circ} 00^{\prime} \mathrm{W}$ and $11^{\circ} 19^{\prime} \mathrm{W}$ longitude

\section{Temporal coverage}

17 th to 21 st century.

\section{Sampling methods}

Study extent description

See the section 'Spatial coverage' and 'Project details - Study area description'.

\section{Sampling description}

The data are sampled manually from literature by the editors, though recent additions are based on specimens maintained at institutional herbaria across Canada (see Thiers).

All floras covering Canada, Greenland, and Saint Pierre and Miquelon were considered for literature-based data entry, but only the most recent provincial and territorial floras (see the section 'References - References used to build the dataset') were 
systematically searched to establish the distribution status of each taxon in each region (see the section 'Spatial coverage'). Scoggan's Flora of Canada (1978-1979) was systematically searched, as were Kartesz (1999) and the Flora of North America (FNA Ed. Comm. 1993+). English and French vernacular names are based on usage in Canada and, for introduced taxa, on vernaculars from the countries of origin (when the taxon is from Europe). Alternate (synonym) vernaculars are provided when several names are in usage (notably regional names), but an accepted vernacular is recommended for general usage throughout the country. The method of selection of vernacular names follows Darbyshire et al. (2000). The source of the information is referenced for all scientific names, vernacular names and distributions in the dataset.

\section{Quality control description}

New findings or corrections for plant distributions are communicated to the editors by contributors from each region (Appendix). Contributors are local botanists, often associated with Canadian herbaria or Conservation Data Centers. All new reports must be documented by specimens deposited at institutional herbaria.

Suggestions or corrections regarding names, taxonomy, or functionality of the VASCAN website are submitted by users and reviewers through a public Google Code issue tracker at http://code.google.com/p/canadensys/issues/list?can=2\&q=label:vascan. Name suggestions are validated by the editors against names in Tropicos (http://www. tropicos.org), IPNI (http://www.ipni.org), GRIN (http://www.ars-grin.gov), or other plant name databases, before being manually corrected in the database.

\section{Dataset}

The data are stored in a relational database (MySQL), which powers the search, checklist builder, taxon and name pages of the VASCAN website. Editors update a development copy of the database through a secure web application. This allows them to make revisions without affecting the users of the website. Once they agree that the data are consistent, in which they are aided by the application, they can push that version of the database to production.

At that moment, the application will also automatically generate a Darwin Core Archive of the data, using the GBIF GNA Profile (GBIF 2010) and following best practices for publishing checklists (GBIF 2011). This archive (Figure 3) includes all data, except for calculated distributions, hybrid parents, and user credentials. The archive is then manually uploaded to the Canadensys Repository (http://data.canadensys.net/ipt), a GBIF Integrated Publishing Toolkit, and republished, at which time it will be assigned a new version number (version 24 at the time of publication). The dataset is registered with the Global Biodiversity Information Facility (GBIF), which allows that organization to harvest, display and distribute the data at any time. 

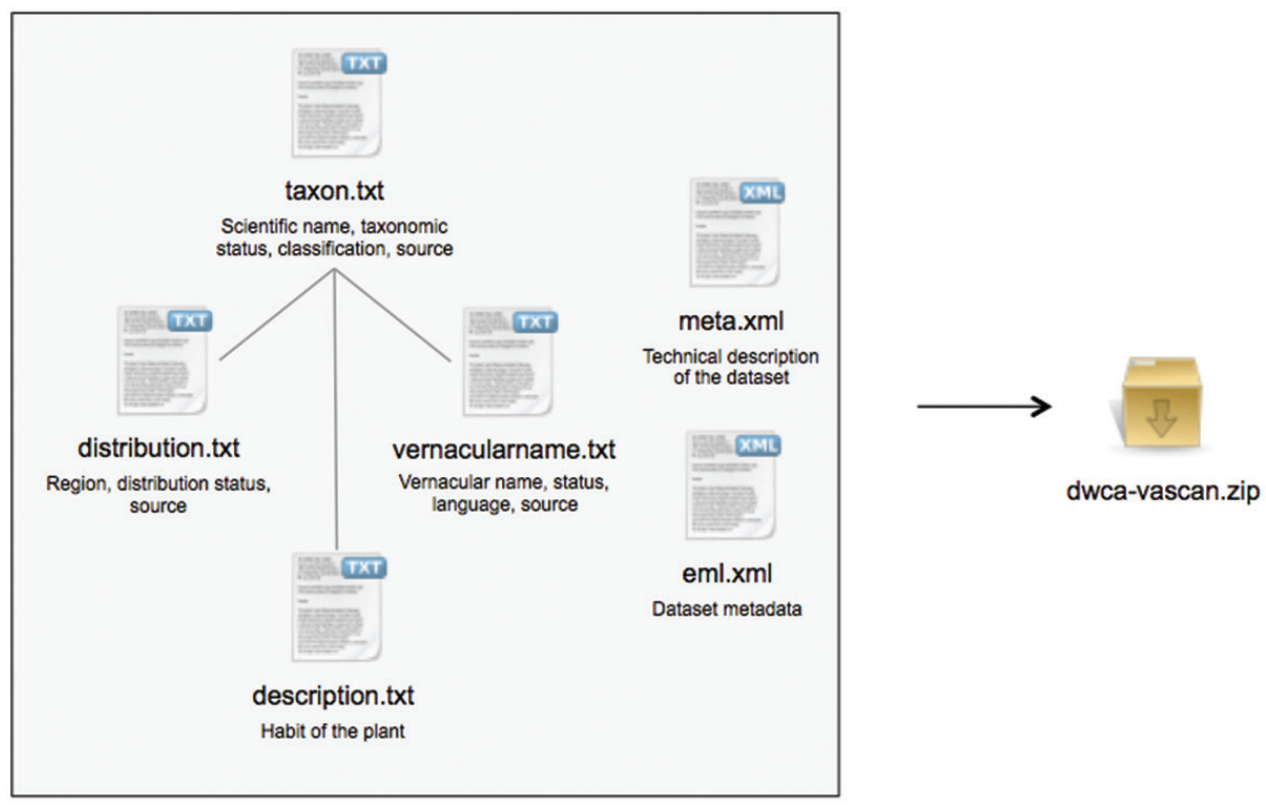

Figure 3. The VASCAN Darwin Core Archive, structured following the GBIF GNA Profile. It is a compressed folder containing 4 text files with tab-seperated values and $2 \mathrm{xml}$ files. Taxon and scientific name information is provided in taxon.txt, with one record for each taxon and child-parent-relationships representing the classification. Records in the extension files distribution.txt, vernacularname.txt and description.txt have a many-to-one relation with the records in taxon.txt and provide additional information for each taxon. The archive structure and term definitions are described in meta.xml. The dataset metadata are provided in eml.xml.

To the extent possible under law, the Université de Montréal Biodiversity Centre has waived all copyright and related or neighboring rights to this dataset, releasing it to the public domain under a CC0 waiver. Users of the data are encouraged to follow the Canadensys norms for data use and publication (http://www.canadensys.net/norms):

Give credit where credit is due: As is common practice in scientific research, cite the data you are using.

Be responsible: Use the data responsibly. The data are published to allow anyone to better study and understand the world around us, so please do not use the data in any way that is unlawful, harmful or misleading. Understand that the data are subject to change, errors and sampling bias. Protect the reputation of the data publisher and clearly indicate any changes you may have made to the data.

Share knowledge: Let us know if you have used the data. It helps us to showcase our efforts and it helps you reach a wider audience. Inform us if you have comments about the data, notice errors, or want more information.

Respect the data license: Understand and respect the data waiver under which the data are published. To help you make greater use of the data, we have dedicated the data to the public domain (CCO). Do not remove the public domain mark or provide misleading information about the copyright status. 
Object name: Darwin Core Archive for the Database of Vascular Plants of Canada (VASCAN)

Character encoding: UTF-8

Format name: Darwin Core Archive format

Format version: 1.0

Distribution: doi: 10.5886/Y7SMZY5P

Publication date of data: 2013-07-22

Language: English

Licenses of use: http://creativecommons.org/publicdomain/zero/1.0/ \& http://www. canadensys.net/norms

Metadata language: English

Date of metadata creation: $2013-07-22$

Hierarchy level: Dataset

Suggested citation for the latest version of the dataset

Brouillet L, Desmet P, Coursol F, Meades SJ, Favreau M, Anions M, Bélisle P, Gendreau C, Shorthouse D and contributors (2010+) Database of Vascular Plants of Canada (VASCAN). Online at http://data.canadensys.net/vascan, doi: 10.5886/1bft7W5f, and http://www.gbif.org/dataset/3f8a1297-3259-4700-91fc-acc4170b27ce, released on 2010-12-10. Version [xx]. GBIF key: 3f8a1297-3259-4700-91fc-acc4170b27ce. Data paper ID: http://dx.doi.org/10.3897/phytokeys.25.3100 [accessed on [date]]

\section{Acknowledgements}

The authors wish to thank the reviewers and editor for their constructive feedback.

\section{References}

\section{References cited within the metadata}

Angiosperm Phylogeny Group (2009) An update of the Angiosperm Phylogeny Group classification for the orders and families of flowering plants: APG III. Botanical Journal of the Linnaen Society 161: 105-121. doi: 10.1111/j.1095-8339.2009.00996.x

Chase MW, Reveal JL (2009) A phylogenetic classification of land plants to accompany APG III. Botanical Journal of the Linnaen Society 161 (2): 122-127. doi: 10.1111/j.10958339.2009.01002.x

Christenhusz MJM, Reveal JL, Farjon A, Gardner MF, Mill RR, Chase MW (2011a) A new classification and linear sequence of extant gymnosperms. Phytotaxa 19: 55-70.

Christenhusz MJM, Zhang X-C, Schneider H (2011b) A linear sequence of extant families and genera of lycophytes and ferns. Phytotaxa 19: 7-54. 
COSEWIC (2009+) Committee on the Status of Endangered Wildlife in Canada. http://www. cosewic.gc.ca/eng/sct6/index_e.cfm [accessed June 17, 2013]

Darbyshire SJ, Favreau M, Murray M (2000) Common and scientific names of weeds in Canada. Research Branch, Agriculture and Agri-Food Canada, Ottawa, Ont. Publ. 1397/B. 132 pp.

Environment Canada (2011) Canada's Protected Areas. http://www.ec.gc.ca/indicateurs-indicators/default.asp?lang=en\&n=478A1D3D-1 [accessed June 17, 2013]

Flora of North America Editorial Committee (1993+) Flora of North America north of Mexico. 30 volumes. Oxford University Press, New York. http://www.fna.org

GBIF (2010) GBIF GNA Profile Reference Guide for Darwin Core Archives, version 1.2, released on 1 April 2011, (contributed by Remsen DP, Döring M, Robertson T), Copenhagen: Global Biodiversity Information Facility, 28 pp. http://links.gbif.org/gbif_gna_ profile_reference_guide

GBIF (2011) Publishing Species Checklists, (contributed by Remsen D, Döring M, Robertson, T, Ko B), Copenhagen: Global Biodiversity Information Facility, 53 pp. http://links. gbif.org/checklist_how_to

International Plant Names Index (IPNI) (2012) Published on the Internet. http://www.ipni. org [accessed 15 March 2013]

Kartesz JT (1999) A synonymized checklist and atlas with biological attributes for the vascular flora of the United States, Canada, and Greenland. In: Kartesz JT, Meacham CA. Synthesis of the North American Flora, Version 1.0. North Carolina Botanical Garden. Chapel Hill. (CD-ROM).

Rothfells CJ, Sundue MA, Kuo L-Y, Larsson A, Kato M, Schuettpelz E, Pryer KM (2012) A revised family-level classification for eupolypod II ferns (Polypodiidae: Polypodiales). Taxon 61: 515-533.

Scoggan HJ (1978-1979) The Flora of Canada. National Museum of Natural Sciences, Publications in Botany 7, 4 volumes.

Smith AR, Pryer KM, Schuettpelz E, Korall P, Schneider H, Wolf PG (2006) A classification for extant ferns. Taxon 55: 705-731. doi: 10.2307/25065646

Thiers B [continuously updated]. Index Herbariorum: A global directory of public herbaria and associated staff. New York Botanical Garden's Virtual Herbarium. http://sweetgum.nybg. org/ih/ [accessed 15 March 2013]

Tropicos.org. Missouri Botanical Garden. http://www.tropicos.org [accessed 15 March 2013] USDA, ARS (U.S. Department of Agriculture, Agricultural Research Service), National Genetic Resources Program (2013) Germplasm Resources Information Network - (GRIN) [Online Database]. National Germplasm Resources Laboratory, Beltsville, Maryland. http:// www.ars-grin.gov [accessed 22 April 2013]

USDA, NRCS (U.S. Department of Agriculture, Natural Resources Conservation Services) (2011) The PLANTS Database (http://plants.usda.gov). National Plant Data Team, Greensboro, NC 27401-4901 USA.

World Bank (2013) World Development Indicator Data: Terrestrial protected areas (\% of total land area). http://data.worldbank.org/indicator/ER.LND.PTLD.ZS [accessed June $17,2013]$ 


\section{References used to build the dataset}

See also the references above. Only the main references are listed; at the time of publication, 485 references are cited in the dataset.

Aiken SG, Dallwitz MJ, Consaul LL, McJannet CL, Boles RL, Argus GW, Gillett JM, Scott PJ, Elven R, LeBlanc MC, Gillespie LJ, Brysting AK, Solstad H, Harris JG (2007) Flora of the Canadian Arctic Archipelago: Descriptions, Illustrations, Identification, and Information Retrieval. CD-ROM. NRC Research Press and Canadian Museum of Nature, Ottawa, Ont. http://nature.ca/aaflora/data/index.htm

Böcher TW, Fredskild B, Holmen K, Jakobsen K (1978) Grønlands Flora. Haase P, Forlag S, Copenhagen.

Cody WJ (2000) Flora of Yukon. 2nd edition. NRC Press, Ottawa.

Douglas GW, Meidinger D, Pojar J, editors (1998-2003) Illustrated Flora of British Columbia. 8 volumes. British Columbia Ministry of Sustainable Resource Management \& Min. Forests, Victoria, B.C.

Erskine DS (1960) 1985 The Plants of Prince Edward Island (revised by P. M. Catling, 1985). Can. Dept. Agr. Publ. 1798.

Etcheberry R (1989) Plantes de Saint-Pierre et Miquelon. Unpublished manuscript.

Etcheberry R, Abraham D, Muller S (2010) Nouvelles espèces de plantes vasculaires pour les îles Saint-Pierre-et-Miquelon et commentaires sur la flore de l'archipel. Bulletin de la Société des naturalistes luxembourgeois 111: 85-105.

Harms VL (2003) Checklist of the Vascular Plants of Saskatchewan and the provincially and nationally rare native plants in Saskatchewan. University Extension Press, U. of Saskatchewan, Saskatoon. 328 p.

Hinds HR (2000) Flora of New Brunswick. 2nd. ed. University of New Brunswick, Fredericton. Klinkenberg B, editor (2008) E-Flora BC: Electronic Atlas of the Plants of British Columbia. Lab. Advanced Spatial Analysis, Dept. Geography, U. British Columbia. http://ww.eflora.bc.ca

Marie-Victorin Fr (1995) Flore laurentienne. 3e éd. mise à jour et annotée par Brouillet L, Hay SG, Goulet I, Blondeau M, Cayouette J, Labrecque J. Presses de l'Univ. de Montréal, Montreal.

Meades SJ, Hay SG, Brouillet L (2000) Vascular Plants of Newfoundland and Labrador. http:// www.digitalnaturalhistory.com/meades.htm

Moss EH (1983) Flora of Alberta. 2nd ed. University of Toronto Press.

Newmaster SG, Lehela A, Oldham MJ, Uhlig PWC, McMurray S (1998) Ontario Plant List. Ontario Forest Research Institute, Sault Ste. Marie, Ontario. Forest Information Paper No. 123.550 pp.

Newmaster SG, Ragupathy (2012+) Flora Ontario Integrated Botanical Information System (FOIBIS). http://www.uoguelph.ca/foibis/

Porsild AE, Cody WG (1980) Vascular Plants of Continental Northwest Territories, Canada. Canadian National Museum of Natural Sciences. Ottawa, Ont.

Roland AE (1998) Roland's Flora of Nova Scotia. Revised by Zinck M. Nimbus Publishing \& N.S. Museum. Halifax, N.S. 


\section{Appendix}

\section{Contributors}

The following individuals made a significant contribution to VASCAN, in addition to the personnel listed in the section 'Project details - Personnel': G. Argus (Canadian Museum of Nature), S. Blaney (Atlantic Canada Conservation Data Center), B. Bennett (Environment Yukon), J. Cayouette (Eastern Cereal and Oilseed Research Centre), A. Cuerrier (Montreal Botanical Garden), R. Etcheberry (Saint Pierre and Miquelon), B. Ford (University of Manitoba), B. Fredskild (Denmark), K. Gandhi (Harvard University Herbaria), L. Gillespie (Canadian Museum of Nature), J. Gould ( Alberta Tourism, Parks and Recreation), J. Greenall (Manitoba Conservation Data Centre), G. Halliday (Great Britain), C. Hanel (Newfoundland and Labrador Department of Environment and Conservation), V. Harms (University of Saskatchewan), S.G. Hay (Université de Montréal Biodiversity Centre), J. Labrecque (Centre de données sur le patrimoine naturel du Québec), F. Lomers (British Columbia), J. Maunder (The Rooms Provincial Museum, Newfoundland), M. Munro (Nova Scotia Museum), M. Oldham (Ontario Natural Heritage Information Centre), E. Punter (University of Manitoba), and J.C. Semple (University of Waterloo), as well as many people who made single contributions. 